\title{
Opioid losses in terms of dosage and value, January 2012 to September 2017: a retrospective analysis of Health Canada data
}

\author{
Mark Fan MHSc, Dorothy Tscheng BScPhm, Michael Hamilton MD MPH, Patricia Trbovich PhD
}

Abstract

Background: Canadian health care facilities must report losses or thefts of opioids to Health Canada. To broaden the understanding of opioid loss in Canada, we analyzed data describing these losses to estimate the amount of opioid lost, estimate the wholesale and street value, compare the distribution of loss types between facility types and compare loss trends.

Methods: We analyzed Health Canada records of losses of codeine, fentanyl, hydromorphone, morphine and oxycodone reported by Canadian facilities from January 2012 to September 2017. We conducted descriptive analyses of the opioid losses by calculating milligrams of drug lost, oral morphine equivalents, daily defined doses, approximate wholesale value and approximate street value, and compared loss trends when counted by incidents, dosage units or milligrams.

Results: There were 64963 reports of loss of codeine, fentanyl, hydromorphone, morphine or oxycodone over the study period. Over $112 \mathrm{~kg}$ of opioids were lost, an estimated \$8.7 million in wholesale cost and \$136 million in street value. The dominant loss categories varied by facility type: armed robbery (30.9 $\mathrm{kg}$ [31.1\%]) for community pharmacies, unexplained losses (6.4 kg [55.8\%]) for companies and pilferage $(0.8 \mathrm{~kg}[57.4 \%])$ for hospitals. Loss trends over the study period varied by reporting metric and facility type: community pharmacy losses increased when measured by dosage units and incidents of loss, and remained stable when measured by milligrams; hospital losses increased when measured by milligrams and showed no clear trend when measured by dosage units and incidents of loss. Companies showed no clear loss trend with any reporting metric.

Interpretation: Large quantities of opioids were lost or stolen from community pharmacies, companies and hospitals over the study period, and these losses are valued in millions of dollars. Publishing milligrams of opioids lost annually alongside metrics such as dosage units and incidents of loss would help characterize the economic cost and the magnitude of drug losses.

$\mathrm{D}$ rug losses and thefts cost health care facilities in investigations, care for patients with inadequately treated pain or harmed by drug substitution or tampering, and reputation-related damages. ${ }^{1-9}$ Furthermore, losses from health care facilities have the potential to increase illegal supply of opioids via trafficking. In the United States, the Drug Enforcement Agency reports annually on opioid losses from health care institutions (e.g., community pharmacies, hospitals). ${ }^{10,11}$ The Canadian authority that captures data on opioid losses from health care facilities, Health Canada, does not publish an equivalent report. Dating back to at least $1961,{ }^{12}$ any individuals or organizations in Canada licensed to produce, package, assemble, sell or transport opioids are mandated to report losses to Health Canada by fax or email within 10 days ${ }^{13}$ (see reporting form in Appendix 1, section 9, available at www.cmajopen.ca/content/8/1/E113/suppl/DC1). This group includes, but is not limited to, a wide variety of facilities such as hospitals, community pharmacies, all companies (e.g., drug manufacturers), long-term care homes and veterinary hospitals.

Health Canada conducts random, targeted inspections of community pharmacies to assess compliance with the mandate, ${ }^{14}$ but data on hospital inspections are scarce. Local regulatory

Competing interests: Mark Fan and Patricia Trbovich have received honoraria from Becton Dickinson Canada for presenting preliminary study findings at events sponsored by Becton Dickinson Canada. No other competing interests were declared.

This article has been peer reviewed.

Correspondence to: Mark Fan, mark.fan@nygh.on.ca

CMAJ Open 2020. DOI:10.9778/cmajo.20190112 
bodies may also conduct inspections (e.g., the Ontario College of Pharmacists inspects both community and hospital pharmacies), but practices in the provinces and territories vary. Police services or insurance companies do not enforce the reporting mandate and may not be alerted to the losses. Pilot work suggests that Health Canada data represent the best source of information on the incidence of Canadian opioid losses (Appendix 1, section 1).

Opioid losses have been reported in "dosage units"11,15,16 and "incidents of loss," 17 both of which have important limitations that may not be widely understood. Dosage units indiscriminately count loss quantities (e.g., the loss of 1 tablet is counted the same as the loss of 1 bottle containing 500 tablets). Incidents of loss ignores the quantity of loss completely and may also be affected by reporting frequency (e.g., hospital A may submit a single report for multiple losses of a drug within a 10-d window, whereas hospital B may submit separate reports after each occurrence).

To broaden the understanding of opioid losses in Canada, we analyzed Health Canada data to estimate milligram losses for 5 common opioids; estimate the wholesale and street value of lost opioids; compare milligrams lost and reason for loss by facility type; and compare opioid loss trends as measured by incidents of loss, dosage units and milligrams.

\section{Methods}

\section{Data source}

In June 2018, the CBC published Health Canada data from an Access to Information request for all controlled drug losses between Jan. 1, 2012, and Sept. 30, 2017..$^{18,19}$ This is the largest published data set identified and is therefore valuable for assessing trends in Canadian health care sources. The CBC confirmed that the data were uploaded without alteration as they were received from Health Canada (Tara Carman: personal communication, 2019); the data are consistent in format with previous Access to Information requests.

\section{Inclusion criteria and constraints}

We limited our analysis to the most commonly dispensed opioids in Canada based on data from the Canadian Institute for Health Information: ${ }^{20}$ codeine, fentanyl, hydromorphone, morphine and oxycodone. Tramadol is among the 6 most dispensed opioids in Canada ${ }^{20}$ but is not yet classified as a controlled substance, ${ }^{21}$ so no loss reports were captured for this drug.

\section{Outcomes}

The Health Canada data state a numeric quantity lost for each incident of loss, but the unit code (e.g., millilitres, tablets, patches) for each report varies. Two authors (M.F. and D.T.), with the support of pharmacy students, used this information to calculate manually the milligrams lost for every reported drug loss (they updated a single file repeatedly and reviewed it continuously in a collaborative manner). For anomalous reports, M.F., D.T. and M.H. came to consensus on how to proceed. We then used the calculated milligrams lost to deter- mine oral morphine equivalents and daily defined doses (see Appendix 1, section 3, for conversion factors). Daily defined doses are defined by the World Health Organization as the "assumed average maintenance dose per day for a drug used for its main indication in adults"22 and is used to facilitate international comparisons.

We used the lowest estimate of loss for ambiguous or anomalous reports. For example, 1 report listed the loss of 728 packages of hydromorphone hydrochloride, $50 \mathrm{mg} / \mathrm{mL}$. From the data set, it was unclear whether these containers were $1 \mathrm{~mL}, 5 \mathrm{~mL}, 10 \mathrm{~mL}$ or $50 \mathrm{~mL}$. In this case, the smallest available package according to the drug product monographs found on Health Canada's Drug Product Database ${ }^{23}$ is a box of ten $1-\mathrm{mL}$ vials. To estimate the impact of a nonconservative approach, we recalculated the losses for the top $40 \%$ of anomalous reports most affected by the conservative approach for each of the 5 opioids (additional details are provided in Appendix 1, section 2).

For 2017, the data set contains data only for January to September. We therefore provide a prorated estimate for a full year of 2017 only when data are presented by year. We averaged the milligram losses in the first 3 quarters of 2017 and added this value as the loss for the final quarter (October to December).

The definitions from Health Canada for the various loss categories (e.g., unexplained loss, pilferage) in the data set are included in Appendix 1, Supplemental Table S11. Not all loss categories in the data set are captured in Health Canada's guidance document, but we left these reports in the analysis for comprehensiveness. We assumed the loss description was accurate in the absence of an alternative strategy.

\section{Wholesale and street drug costing}

We calculated approximate wholesale costs from the Ontario Drug Benefit database (2019 data) for the entire data set because most oral morphine equivalent losses came from Ontario. If the cost was not available from the Ontario Drug Benefit database, we searched other provincial formularies (see our analytical dataset, available at https://github.com/HumanEra/Health -Canada-Drug-Loss-and-Theft-Data-Analysis, for wholesale pricing information). Although street value fluctuates ${ }^{24,25}$ depending on cycles of supply and demand, geography and drug strength, we used a single point-in-time street value based on information from the Ontario Provincial Police and the literature (Appendix 1, section 4).

\section{Statistical analysis}

We conducted descriptive analyses of the opioid losses by calculating milligrams of drug lost, oral morphine equivalents, daily defined doses, approximate wholesale value and approximate street value. We used Microsoft Excel for analyses.

\section{Ethics approval}

No personal health information or human participants were involved in the study. No specific institutions are identified, and the data are publicly accessible from Health Canada on request. As a result, ethics board approval was not required. 


\section{Results}

Restricting our analysis to codeine, fentanyl, hydromorphone, morphine and oxycodone resulted in 64963 reports, which is $45.6 \%$ of the reports in the original data set (142 420). An analysis of the 64963 reports using a conservative approach when imputing anomalous records showed that the cumulative loss of the 5 opioids between January 2012 and September 2017 was over $112 \mathrm{~kg}$ (Table 1). This equates to about $\$ 8.7$ million in wholesale costs and $\$ 136$ million if all lost drugs were resold on the street. When we used a more liberal approach on a sample of anomalous reports, milligram losses increased by $7.5 \mathrm{~kg}$, the wholesale value increased by $\$ 886670$, and the street value of the losses increased by \$9 695290 (Appendix 1, Supplemental Table S5).

Community pharmacies, companies and hospitals were responsible for nearly all losses, accounting for $76.8 \%, 17.1 \%$ and $6.0 \%$ of lost oral morphine equivalents, respectively (Table 2). As a result, all subsequent analyses were focused on these 3 facility types.

The dominant reasons for loss (in milligrams) varied by facility type (Table 3 ). Community pharmacy losses were primarily from armed robberies (31.1\%), break and entry (28.1\%), unexplained losses (17.6\%) and pilferage $(15.5 \%)$. Company losses were primarily from unexplained losses $(55.8 \%)$ and losses in transit (30.7\%). Hospitals were affected primarily by pilferage (57.4\%) and unexplained losses $(33.4 \%)$.

More detailed breakdowns of loss trends by province or territory for community pharmacies and hospitals showed that there were substantial reductions in community pharmacy losses in British Columbia over the study period, whereas Ontario hospitals reported an increasing amount of pilferage losses in the more recent years of the study period (Appendix 1, sections 5 and 6).

\begin{tabular}{|c|c|c|c|c|c|}
\hline Drug; route* & $\begin{array}{l}\text { Milligrams } \\
\text { lost } \\
\text { (per 1000)† }\end{array}$ & $\begin{array}{l}\text { Oral morphine } \\
\text { milligram } \\
\text { equivalent } \\
\text { (per 1000)† }\end{array}$ & $\begin{array}{l}\text { Daily defined } \\
\text { dose }\end{array}$ & $\begin{array}{l}\text { Estimated } \\
\text { wholesale } \\
\text { value, } \$\end{array}$ & $\begin{array}{c}\text { Estimated street } \\
\text { value, } \$\end{array}$ \\
\hline \multicolumn{6}{|l|}{ Codeine } \\
\hline Oral & 47072.3 & 7060.8 & 196135 & 1313140 & 52956369 \\
\hline Injection & 3.7 & 0.9 & 58 & 514 & 4185 \\
\hline Indeterminate & 228.7 & 34.3 & 953 & 6369 & 257306 \\
\hline \multicolumn{6}{|l|}{ Fentanylł } \\
\hline Oral & 66.8 & 8687.6 & 111379 & 3212163 & 26731 \\
\hline Injection & 10.6 & 1065.5 & 66336 & 302036 & 4257 \\
\hline Transdermal & 184.0 & 18403.2 & 153360 & 199936 & 5111997 \\
\hline Indeterminate & 2.7 & 349.8 & 4484 & 129346 & 1077 \\
\hline \multicolumn{6}{|l|}{ Hydromorphone } \\
\hline Oral & 12160.0 & 60799.4 & 607994 & 1447179 & 18239833 \\
\hline Injection & 544.4 & 9526.8 & 136097 & 199890 & 816581 \\
\hline Rectal & 0.5 & 2.8 & 117 & 593 & 702 \\
\hline Indeterminate & 19.2 & 96.0 & 960 & 2288 & 28803 \\
\hline \multicolumn{6}{|l|}{ Morphine } \\
\hline Oral & 15154.6 & 15154.6 & 151546 & 353846 & 12578317 \\
\hline Injection & 325.6 & 976.7 & 10852 & 205417 & 270224 \\
\hline Rectal & 73.0 & 87.7 & 2435 & 11318 & 60627 \\
\hline Indeterminate & 134.7 & 134.7 & 1347 & 3151 & 111794 \\
\hline \multicolumn{6}{|l|}{ Oxycodone } \\
\hline Oral & 36537.3 & 54805.9 & 487164 & 1312734 & 45671623 \\
\hline Rectal & 9.6 & 17.2 & 319 & 3229 & 11975 \\
\hline Total & 112527.7 & 177204.1 & 1931538 & 8703149 & 136152401 \\
\hline \multicolumn{6}{|c|}{$\begin{array}{l}\text { *"Oral" refers to tablets, capsules, and sublingual and oral solutions (e.g., syrups); "injection" includes intravenous and subcutaneous } \\
\text { formats; "indeterminate" refers to line items in the data set for which the route or format of the drug was ambiguous. } \\
\text { †Column and row totals may not match the sum of numbers in the table because the table shows only rounded numbers. } \\
\text { fFentanyl is typically dosed in micrograms, but for consistency with other drugs we report in milligrams. }\end{array}$} \\
\hline
\end{tabular}




\begin{tabular}{|c|c|c|c|c|c|c|}
\hline \multirow[b]{2}{*}{ Facility type } & \multicolumn{6}{|c|}{ Opioid; oral morphine equivalent (per 1000 mg) lost } \\
\hline & Codeine & Fentanyl & Hydromorphone & Morphine & Oxycodone & $\begin{array}{c}\text { Total }^{*} \\
\text { (\% of column total) }\end{array}$ \\
\hline Community pharmacy & 6222.4 & 16983.0 & 46535.1 & 14255.2 & 52112.9 & $136108.5(76.8)$ \\
\hline Company & 815.0 & 10041.6 & 15741.9 & 1432.7 & 2298.5 & $30329.8(17.1)$ \\
\hline Hospital & 42.5 & 1468.2 & 8143.4 & 647.9 & 395.2 & $10697.2(6.0)$ \\
\hline Long-term care facility & 11.7 & 2.0 & 3.2 & 0.9 & 15.5 & $33.3(0.0)$ \\
\hline Nurse station $†$ & 3.7 & 2.0 & 0.4 & 8.6 & 0.6 & $15.2(0.0)$ \\
\hline Canadian Forces base & 0.8 & 7.3 & 1.1 & 1.2 & 0.5 & $10.8(0.0)$ \\
\hline Ambulatory service $\neq$ & - & 2.0 & $\sim 0.0$ & 7.2 & - & $9.2(0.0)$ \\
\hline Total $^{*}$ & 7096.1 & 28506.1 & 70425.0 & 16353.7 & 54823.2 & 177204.1 \\
\hline \multicolumn{7}{|c|}{$\begin{array}{l}\text { *Column and row totals may not match the sum of numbers in the table because the table shows only rounded numbers. } \\
\text { †Nurse stations are found in small rural and isolated communities where access to health care is otherwise limited; they are staffed by registered nurses or nurse } \\
\text { practitioners typically providing primary care and have limited on-site availability of a physician partner. } \\
\text { †Ambulatory services are typically clinics affiliated with an institution or hospital and provide procedures or services on an outpatient basis, or are stand-alone clinics } \\
\text { providing similar services. }\end{array}$} \\
\hline
\end{tabular}

\begin{tabular}{|c|c|c|c|c|}
\hline \multirow[b]{2}{*}{ Reason for loss* } & \multicolumn{4}{|c|}{ Facility type; $\%$ of losses ( $\%$ of column total) } \\
\hline & Community pharmacy & Company & Hospital & Total† \\
\hline Armed robbery & $30935.2(31.1)$ & $10.9(0.1)$ & $\sim 0(0.0)$ & 30946.2 \\
\hline Break and entry & $27978.9(28.1)$ & $147.5(1.3)$ & $64.1(4.5)$ & 28190.4 \\
\hline Breakage in transit & $275.6(0.3)$ & $58.6(0.5)$ & $0.3(0.0)$ & 334.5 \\
\hline Breakage on site & $5.9(0.0)$ & - & $0.6(0.0)$ & 6.5 \\
\hline Grab theft & $1381.3(1.4)$ & $790.6(6.9)$ & $34.3(2.4)$ & 2206.2 \\
\hline Impersonation & $74.4(0.1)$ & - & - & 74.4 \\
\hline Loss in transit & $159.2(0.2)$ & $3540.8(30.7)$ & $15.2(1.1)$ & 3715.2 \\
\hline Loss unexplained & $17481.0(17.6)$ & $6429.2(55.8)$ & 475.4 (33.4) & 24385.6 \\
\hline $\begin{array}{l}\text { Manufacturer's defect } \\
\text { (ampoules) }\end{array}$ & $\sim 0(0.0)$ & $0.1(0.0)$ & $\sim 0(0.0)$ & 0.1 \\
\hline $\begin{array}{l}\text { Manufacturer's shortage } \\
\text { (sealed bottles) }\end{array}$ & $28.6(0.0)$ & $34.5(0.3)$ & $1.1(0.1)$ & 64.2 \\
\hline $\begin{array}{l}\text { Overshipment } \\
\text { (picking error) }\end{array}$ & $0.4(0.0)$ & $2.8(0.0)$ & - & 3.2 \\
\hline Pilferage & $15459.0(15.5)$ & $260.2(2.3)$ & $817.6(57.4)$ & 16536.8 \\
\hline Spillage & $6.1(0.0)$ & - & $0.2(0.0)$ & 6.3 \\
\hline Undershipment & $4.1(0.0)$ & $0.4(0.0)$ & - & 4.4 \\
\hline Other & $5659.0(5.7)$ & $248.3(2.2)$ & $14.3(1.0)$ & 5921.6 \\
\hline Total† & $99448.8(100.0)$ & 11523.9 (100.0) & $1423.2(100.0)$ & 112395.6 \\
\hline
\end{tabular}

We observed different trends when reporting milligrams of lost opioids than when reporting dosage units or number of incidents of loss (Table 4). Specifically, the incidents of loss and dosage units lost from community pharmacies increased steadily from 2012, but milligram losses did not. Conversely, hospitals showed increased milligram losses in the more recent years of the study period, whereas the same trend was not seen for incidents of loss and dosage units. Companies did not show discernible trends in any of these metrics. A visual depiction of trends is presented in Appendix 1, section 7. 


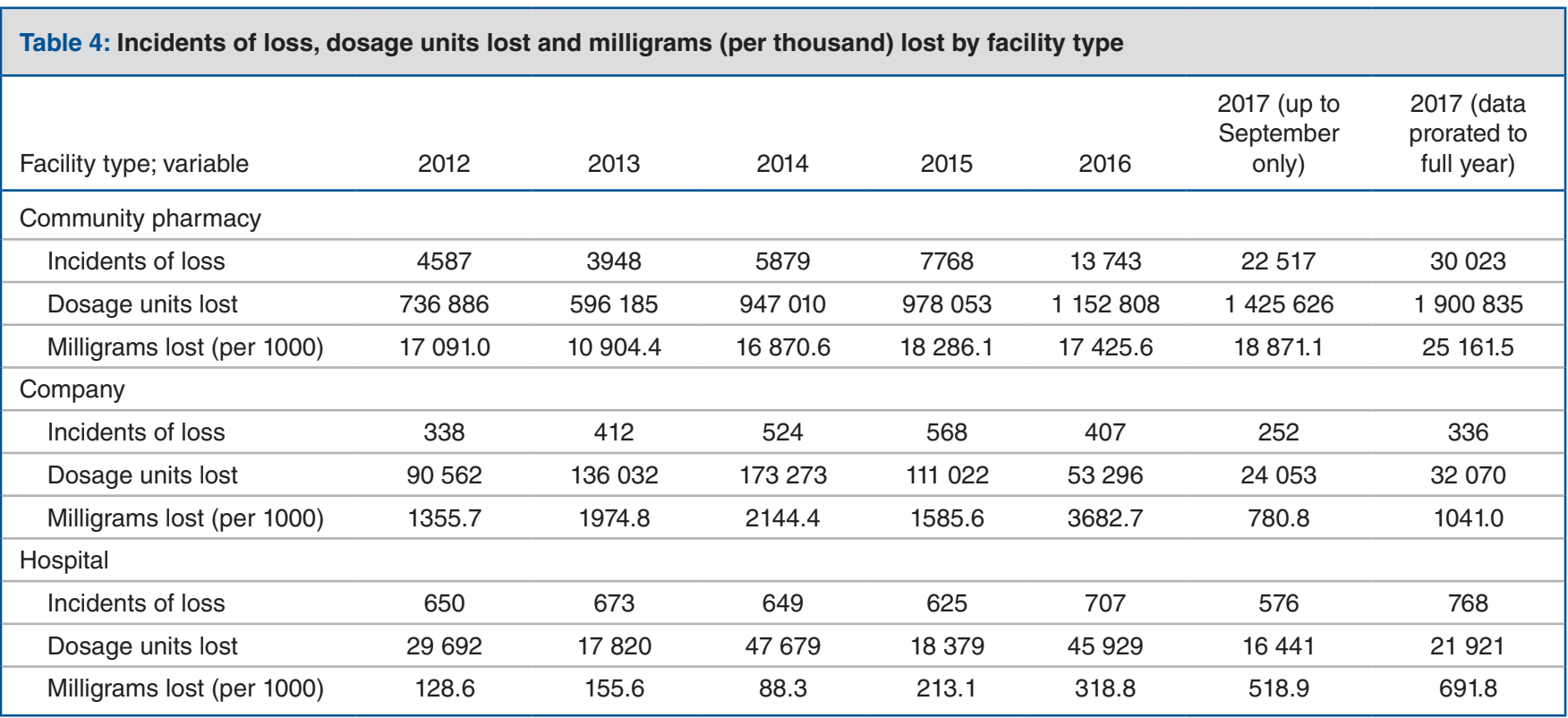

\section{Interpretation}

Our analysis suggests that the lower bound for the average annual loss of 5 common opioids in Canada between January 2012 and September 2017 is $19.6 \mathrm{~kg}$, with a street value of \$23.7 million. Community pharmacies were the largest contributor to the losses, followed by companies and hospitals, which suggests that improving security and accounting of opioids in community pharmacies should be prioritized. However, unexplained losses were a major category of loss in all 3 facility types, which suggests that Canadian facilities as a whole lack adequate capacity to track and secure opioids. Furthermore, each type of facility may benefit from targeted research to address unique vulnerabilities: community pharmacies were most susceptible to armed robbery and break and enter, hospitals faced a high rate of pilferage, and company losses often occurred during drug transit.

The analysis also showed that opioid loss reporting should include the quantity of milligrams lost. Community pharmacy losses remained stable over time when measured in milligrams, but loss rates increased when loss was measured by dosage units or incidents of loss. Hospital losses increased over time when measured in milligrams but not when measured by dosage units or incidents of loss. These findings show that dosage units or incidents of loss alone do not tell the full story; reporting losses in milligrams provides an important complementary means of assessing loss trends over time within and between facility types or provinces.

According to the International Narcotics Control Board, Canada consumed $7747 \mathrm{~kg}$ (legally acquired) of the 5 opioids analyzed for 2017. ${ }^{26}$ The average annual loss in our data set therefore represents $0.25 \%$ of Canada's consumption. However, the true quantities of loss are likely higher than what our analysis estimates and suggest that an annual loss of $19.6 \mathrm{~kg}$ of opioid from Canadian facilities is not trivial.
Previous literature highlights challenges with detecting or reporting losses; hospitals have been fined for insufficient record-keeping and failing to report drug losses. ${ }^{27-29}$ One endoscopy clinic found that more than $\$ 10000$ 's worth of propofol was unaccounted for in a single 4-week period. ${ }^{30}$ These examples suggest that poor traceability obscures detection and reporting of drug losses. Inclusion of nonopioids in future studies would increase the total milligrams lost and the subsequent costs of drug lost.

The 2018 US Drug Enforcement Agency report described an annual average loss of 12.2 million opioid dosage units, ${ }^{11}$ compared to 1.1 million dosage units in our data. This discrepancy is similar to the population difference between the US and Canada, which suggests that rates of opioid loss and theft are similar in the 2 countries.

Our findings suggest 4 areas of work that may help better understand and potentially mitigate opioid losses and thefts. First, Health Canada and provincial and territorial regulatory bodies may want to assess the impact of their inspection practices against opioid losses moving forward. In 2015, Health Canada began a community pharmacy inspection program. ${ }^{31}$ Data show an upward trend in the incidents and dosage units of opioid lost after this program began but no substantial increase in milligrams lost (Table 4). In contrast, in 2016, the Ontario College of Pharmacists started to inspect and accredit Ontario hospital pharmacies; ${ }^{32}$ since then, there has been an increase in milligrams lost to pilferage (Appendix 1, section 6). Further research into the differences between these inspection programs might reveal why such differences were observed and support optimal inspection practices that can be used for all Canadian facilities responsible for opioids. Inspection practices for companies could also be reviewed to ensure they are similarly effective, given that they contribute larger opioid milligram losses than hospitals.

Second, analysis of regional differences may provide insight into best practices that could be adopted nationally. 
British Columbia showed a notable reduction in community pharmacy losses from armed robberies and break and enter incidents (Appendix 1, Supplemental Table S9), possibly owing to the implementation of time-delay safes. ${ }^{33,34}$ Caution in drawing strong conclusions is warranted given that there were increases in other loss categories (e.g., unexplained losses) in BC. However, armed robbery and break and enter are one of the primary reasons for loss in community pharmacies, and regional differences of this nature may provide regulators and facility managers some indication of potentially helpful practices that may be worth adopting.

Third, the prominence of "unexplained losses" in all facilities suggests that further research is needed to understand why Canadian facilities are unable to track the reasons for loss. The high rate of unexplained losses also raises questions about the misclassification of drug losses. For example, reports of accidental breakage or spillage of a controlled drug may actually be false reports made by hospital staff to obscure diversion, particularly if there are not robust processes in place to verify these losses.

Finally, to support these areas of work, we suggest that Canadian stakeholders would benefit from an annual summary of controlled substance losses reported to Health Canada, similar to that published by the US Drug Enforcement Agency. ${ }^{11}$ This report would facilitate regular assessment of losses and monitor changes over time. Given our findings, the report should include milligram losses by province and territory. To facilitate analysis of milligram losses, the Health Canada loss and reporting form should capture the number of milligrams lost per drug and the dosage format of the loss, to reduce the number of ambiguous reports captured in its data. The current reporting form is ambiguous, as the reported quantity could refer to the dosage form (e.g., patch, ampoule) or the unit (e.g., micrograms, millilitres).

\section{Limitations}

Our analysis has several limitations. First, the Health Canada data may be subject to reporting bias. Jurisdictions with high reported losses may not have experienced a true higher loss rate, but, rather, may have been more diligent at reporting the losses they did experience.

Second, not all drug losses are due to diversion, and diverted drugs may be used personally rather than resold on the street market. Our analysis is not intended to estimate actual revenue from street sales of drug lost but, rather, to contextualize the potential losses and highlight the differences between wholesale costs and street value.

Third, our estimates of wholesale costs and street value are simplified, as we applied single point-in-time estimates (without discounting costs over the data set time span) from selected provincial formularies or police services to the whole data set. Wholesale costs were drawn from 2019 formularies, and police services data reflect average street pricing across geographic areas and the database time frame of 2012-2017.

Finally, 567 reports $(0.9 \%$ of the data set) were anomalous, which necessitated assumptions to complete our analysis. The anomalous reports were responsible for about $10 \%$ of the milligram losses in the data set and are described further in Appendix 1, Supplemental Table S4.

\section{Conclusion}

The drug losses estimated conservatively are large and suggest the need for further research given the other, indirect costs of drug diversion. For example, drugs diverted from the health care system can be resold, channelling taxpayer dollars directly into the hands of drug traffickers while increasing the supply and harms of illicit opioids to surrounding communities, and burdening patients and prescribers who require opioids for legitimate medical use. Our findings suggest that annual reporting of milligram losses by province and territory for use by policy-makers and the public will likely further awareness and research on this topic.

\section{References}

1. Berge KH, Dillon KR, Sikkink KM, et al. Diversion of drugs within health care facilities, a multiple-victim crime: patterns of diversion, scope, consequences, detection, and prevention. Mayo Clin Proc 2012;87:674-82.

2. Brummond PW, Chen DF, Churchill WW, et al. ASHP guidelines on preventing diversion of controlled substances. Am 7 Health Syst Pharm 2017;74:325-48.

3. Controlled drugs and substances in hospitals and healthcare facilities: guidelines on secure management and diversion prevention. Ottawa: Canadian Society of Hospital Pharmacists; 2019. Available: www.cshp.ca/sites/default/files/files/publications/ Official Publications/Guidelines/Controlled Drugs and Substances in Hospitals and Healthcare Facilities_2019 02-28.pdf (accessed 2019 Mar. 19).

4. Schaefer MK, Perz JF. Outbreaks of infections associated with drug diversion by US health care personnel. Mayo Clin Proc 2014;89:878-87.

5. Fan M, Tscheng D, Hamilton M, et al. Diversion of controlled drugs in hospitals: a scoping review of contributors and safeguards. 7 Hosp Med 2019; 14 : 419-28.

6. Carman T, Adhopia V. More than half a million prescription drugs are stolen each year - and most are opioids. CBC News 2018 June 27. Available: www. cbc.ca/news/canada/missing-drugs-pharmacies-part1-1.4708041 (accessed 2018 June 28).

7. LaVigne N, Wartell J. Robbery of pharmacies. Problem-oriented guides for police series, problem-specific guide no. 73. Washington: Office of Community Oriented Policing Services; 2015. Available: www.popcenter.org/sites/default/files/ problems/PDFs/robbery_of_pharmacies.pdf (accessed 2019 July 10).

8. Stanton C. $18.7 \mathrm{M}$ pills lost due to healthcare employee misuse and theft. Baltimore: Protentus; 2018. Available: https://blog.protenus.com $/ 18.7 \mathrm{~m}$-pills-lost -due-to-healthcare-employee-misuse-and-theft (accessed 2018 Sept. 11).

9. New K. Investigating institutional drug diversion. 7 Leg Nurse Consult 2015;26: $15-8$.

10. Joranson DE, Gilson AM. Drug crime is a source of abused pain medications in the United States. 7 Pain Symptom Manage 2005;30:299-301.

11. 2018 national drug threat assessment. Springfield (VA): United States Drug Enforcement Administration; 2018. Available: www.dea.gov/sites/default/ files/2018-11/DIR-032-18 2018 NDTA final low resolution.pdf (accessed 2019 Jan. 4).

12. Narcotic Control Act. SOR/61-344. P.C. 1961-1133. Ottawa: Government of Canada; 1961:1285-96.

13. Reporting of loss or theft of controlled substances and precursors (CS-GD005). Ottawa: Health Canada; modified 2019 Dec. 20. Available: www.canada. ca/en/health-canada/services/publications/healthy-living/loss-theft-controlled -substances-precursors.html (accessed 2019 Dec. 18).

14. Community Pharmacy Inspection program annual report, fiscal year 2017-2018. Ottawa: Health Canada; 2019. Available: www.canada.ca/content/dam/hc-sc/ documents/services/publications/healthy-living/loss-theft-controlled-substances -precursors/loss-theft-report-form-controlled-substances-precursors.pdf (accessed 2019 Nov. 29).

15. Carman T, Adhopia V. More than half a million prescription drugs are stolen each year - and most are opioids. CBC News 2018 June 27. Available: www. cbc.ca/news/canada/missing-drugs-pharmacies-part1-1.4708041 (accessed 2018 June 29).

16. Tromp S. Prescription drug losses, thefts on the rise at smaller B.C. hospitals. Globe and Mail [Toronto]. Available: www.theglobeandmail.com/news/british -columbia/prescription-drug-losses-thefts-on-the-rise-at-smaller-bc-hospitals/ article28826576/ (accessed 2017 June 29).

17. Howorun C. 'Unexplained losses' of opioids on the rise in Canadian hospitals. Macleans 2017 Nov. 24. Available: www.macleans.ca/society/health/ unexplained-losses-of-opioids-on-the-rise-in-canadian-hospitals/ (accessed 2017 Nov. 25). 
18. Carman T. Analysis of Health Canada missing controlled substances and precursors data, Jan. 1, 2012-Sept. 30, 2017 [data set]. San Francisco: GitHub; 2018. Available: https://github.com/taracarman/drug_losses (accessed 2018 June 29).

19. Carman T. When prescription opioids run out, users look for the supply on the streets. CBC News 2018 June 28. Available: www.cbc.ca/news/canada/ when-prescription-opioids-run-out-users-look-for-the-supply-on-the-streets -1.4720952 (accessed 2018 June 29).

20. Pan-Canadian trends in the prescribing of opioids and benzodiazepines, 2012 to 2017 - data tables. Ottawa: Canadian Institute for Health Information; 2018. Available: www.cihi.ca/sites/default/files/document/pan-canadian -prescribed-opioid-benzo-data-tables-june18-en-web.xlsx (accessed 2019 Jan. 4).

21. Forward Regulatory Plan 2019-2021: regulations amending Schedule I to the Controlled Drugs and Substances Act and the Schedule to the Narcotic Control Regulations to add tramadol and related substances. Ottawa: Health Canada; modified 2019 July 29. Available: www.canada.ca/en/health-canada/corporate/ about-health-canada/legislation-guidelines/acts-regulations/forward-regulatory -plan/plan/tramadol.html (accessed 2019 May 14).

22. 3. Defined Daily Dose (DDD). Geneva: World Health Organization. Available: www.who.int/medicines/regulation/medicines-safety/toolkit_ddd/ en/ (accessed 2018 Dec. 12).

23. Drug Product Database online query. Ottawa: Health Canada; modified 2019 Mar. 19. Available: https://health-products.canada.ca/dpd-bdpp/index-eng.jsp (accessed 2018 Oct. 5).

24. Lebin JA, Murphy DL, Severtson SG, et al. Scoring the best deal: quantity discounts and street price variation of diverted oxycodone and oxymorphone. Pharmacoepidemiol Drug Saf 2019;28:25-30.

25. Dasgupta N, Freifeld C, Brownstein JS, et al. Crowdsourcing black market prices for prescription opioids. 7 Med Internet Res 2013;15:e178.

26. Table XIV. Levels of consumption of narcotic drugs, in defined daily doses for statistical purposes per million inhabitants per day, 2014-2016. In: Estimated world opioid requirements for 2018 - statistics for 2016. Vienna: International Narcotics Control Board; 2018:230-53. Available: www.incb.org/incb/en/ narcotic-drugs/Technical_Reports/narcotic_drugs_reports.html (accessed 2019 Nov. 29).

27. MGH to pay $\$ 2.3$ million to resolve drug diversion allegations [press release]. Boston: United States Department of Justice, The United States Attorney's Office, District of Massachusetts; 2015. Available: www.justice.gov/usao-ma/ $\mathrm{pr} / \mathrm{mgh}$-pay-23-million-resolve-drug-diversion-allegations (accessed 2017 Sept. 15).

28. Southern District of Georgia announces largest hospital drug diversion civil penalty settlement in U.S. history [press release]. Savannah (GA): United States Department of Justice, The United States Attorney's Office, Southern District of Georgia; 2018. Available: www.justice.gov/usao-sdga/pr/southern-district -georgia-announces-largest-hospital-drug-diversion-civil-penalty (accessed 2018 Sept. 11)

29. Record settlement reached in University of Michigan hospital drug diversion civil penalty case [press release]. Springfield (VA): United States Drug Enforcement Administration; 2018. Available: www.dea.gov/press-releases/2018/ 08/30/record-settlement-reached-university-michigan-hospital-drug-diversion (accessed 2018 Sept. 11).

30. Horvath C. Implementation of a new method to track propofol in an endoscopy unit. Int 7 Evid Based Healthc 2017;15:102-10.
31. Community Pharmacy Inspection Program annual report, fiscal year 2015-2016. Ottawa: Health Canada; modified 2017 May 5. Available: www.canada.ca/en/ health-canada/services/drugs-health-products/reports-publications/compliance -enforcement/community-pharmacy-inspection-program-annual-report-fiscal -year-2015-2016.html (accessed 2019 Nov. 29).

32. Foxman S. Baseline assessments reveal opportunities for hospital pharmacies: key findings around policies and procedures, traceability, compounding and professional responsibilities. In: Pharmacy connection. Toronto: Ontario College of Pharmacists; 2016:9-13. Available: www.ocpinfo.com/library/practice-related/ download/BaselineAssessmentsWinter2016.pdf (accessed 2017 Aug. 30).

33. Lindsay B. Time-delay safes linked to steep drop in robberies from B.C. pharmacies. CBC News 2018 June 27. Available: www.cbc.ca/news/canada/ british-columbia/time-delay-safes-linked-to-steep-drop-in-robberies-from -b-c-pharmacies-1.4725455 (accessed 2019 May 5).

34. Pharmacy security requirements: What's in effect today? Vancouver: College of Pharmacists of British Columbia; 2017. Available: www.bcpharmacists.org/ readlinks/pharmacy-security-requirements-what's-effect-today (accessed 2019 Apr. 18).

Affiliations: HumanEra (Fan, Trbovich), Office of Research and Innovation, North York General Hospital; Institute for Safe Medication Practices Canada (Tscheng, Hamilton); Institute of Health Policy, Management and Evaluation (Trbovich), University of Toronto, Toronto, Ont.

Contributors: All of the authors contributed substantially to the conception and design of the study and to data analysis and interpretation, drafted the manuscript, revised it critically for important intellectual content, approved the final version to be published and agreed to be accountable for all aspects of the work.

Funding: This work was supported by grant ROR2017-04260JH-NYGH from Becton Dickinson Canada.

Acknowledgements: The authors thank Chris Auger of the Ontario Provincial Police for providing estimates of street value per milligram. They also acknowledge Doctor of Pharmacy students Danny Liu, Lauren Datema, Emily Brown and Kiera Robinson for collecting wholesale drug pricing information and parsing the Health Canada data set. Thanks are given to Iveta Lewis for searching the literature on drug street prices. Thanks also to Tara Carman and the CBC for publishing the Health Canada data set that was the basis for this article.

Disclaimer: Becton Dickinson Canada had no involvement in study design; in the collection, analysis or interpretation of data; in the writing of the report; or in the decision to submit the article for publication.

Supplemental information: For reviewer comments and the original submission of this manuscript, please see www.cmajopen.ca/content/8/1/ E113/suppl/DC1. 